\title{
A feasibility study for using agile contractors to promote mass housing contractors
}

\author{
Faraz Pouyandeh* and Mojtaba Hosseinalipour
}

Department of Architecture, Shahid Beheshti University, Tehran, Iran

\begin{tabular}{l}
\hline C H R O N I C L E \\
\hline Article history: \\
Received January 25, 2015 \\
Received in revised format 28 \\
February 2015 \\
Accepted 27 April 2015 \\
Available online \\
April 29 2015 \\
\hline Keywords: \\
Agile \\
Contract \\
Agile project management \\
\end{tabular}
A B S T R A C T

\begin{abstract}
During the past few years, there have been growing changes on managing different projects using the idea of agile manufacturing by moving from the idea of plan to planning. This paper presents an empirical investigation to study whether it is possible to apply the idea of agile in mass construction projects in Iran. The study designs a questionnaire in Likert scale and distributes it among 35 well-known contractors in the field of construction projects. The questionnaire consists of 8 questions, which is considered in terms of four perspectives including culture, projects, tools and processes and employee. Using some statistical test, the study has determined that it would be possible to apply the idea of agile contractors to promote mass housing contractors.
\end{abstract}

\section{Introduction}

Agile management or agile project management is considered as an iterative and incremental technique of managing the design and building the activities for engineering, information technology, and new product/service development projects in relatively highly flexible and interactive manner, for instance agile software development (Augustine, 2005). It needs motivated and highly qualified individuals from the relevant business, with supplier and customer input (Cockburn \& Highsmith, 2001). Agile methods, also called extreme project management, are variants of iterative life cycle where deliverables are submitted in stages (Schuh, 2005; Highsmith, 2002; Boehm \& Turner, 2003a,b). The primary difference between agile and iterative development is that agile techniques complete small portions of the deliverables in each delivery iteration. Agile method has been developed as a reaction to different barriers that developed in more sequential forms of project organization (Sidky \& Smith, 2009). For instance, as technology projects become more complex, end users may face difficulty defining the long term needs without capability of viewing progressive prototypes (Koch, 2005). According to Vinodh et al. (2013) Agile Manufacturing (AM) paradigm is fast instilled in modern organizations, which enables a firm to evolve products/ services quickly in response to the customers' dynamic demands.

\footnotetext{
* Corresponding author. Tel: +0989123122750

E-mail address: faraz.pouyandeh@gmail.com (F. Pouyandeh) 
Drury et al. (2012) investigated decisions made across four stages of the iteration cycle; namely Planning, Execution, Review and Retrospective. They developed a mixed method whereby a focus group was first conducted with 43 Agile developers and managers to detect decisions made at various points of the iteration cycle. Next, six illustrative mini cases were purposefully built as instances of the six barriers detected in these focus groups. This included interviews with 18 individuals in Agile projects from five various firms. The study contributed to Agile software development literature by analyzing decisions made on the iteration cycle and identifying six key barriers to these decisions. They reported that six decision obstacles were unwillingness to commit to decisions; conflicting priorities; unstable resource availability; and lack of: implementation; ownership; empowerment. They mapped these six decision obstacles to descriptive decision making principles to describe where the obstacles could influence on the decision process. The effects of these obstacles included a lack of longer-term, strategic focus for decisions, an ever-growing backlog of delayed work from previous iterations, and a lack of team engagement.

Shrivastava and Rathod (2015) provided a comprehensive set of risk factors that influence on the performance of distributed agile development projects and determined the risk management techniques used in practice for controlling those risks. They described that the risk factors would be attributed to the conflicting properties of distributed software development and agile development. In addition, some new risk factors could be experienced by practitioners and require further exploration as their understanding would help the practitioners to act on time.

Chow and Cao (2008) performed a survey among Agile professionals, by collecting data from 109 Agile projects from 25 countries across the world. They reported that only 10 out of 48 hypotheses were supported, identifying three critical success factors for Agile software development projects: (a) Delivery Strategy, (b) Agile Software Engineering Techniques, and (c) Team Capability. Requirements prioritization is an important thing of agile software development approaches (Racheva et al., 2010). It may maximize the value delivered to different clients and enhances changing requirements. Racheva et al. (2010) presented results of an exploratory cross-case investigation on agile prioritization and business value delivery processes in different software organizations. They reported that some explicit and fundamental assumptions of agile requirement prioritization techniques, as explained in the agile literature on best practices, would not hold in all agile project contexts in their study. These items include (i) the driving effect of the client in the value creation process, (ii) the prevailing position of business value, (iii) the effect of the prioritization process for project aim achievement.

\section{The proposed study}

This paper presents an empirical investigation to study whether it is possible to apply the idea of agile in mass construction projects in Iran. The study designs a questionnaire in Likert scale and distributes it among 35 well-known contractors in the field of construction projects. The questionnaire consists of 8 questions in four fields of culture, projects, tools and processes and employee. The contractors were categorized in four groups (See Fig. 1).

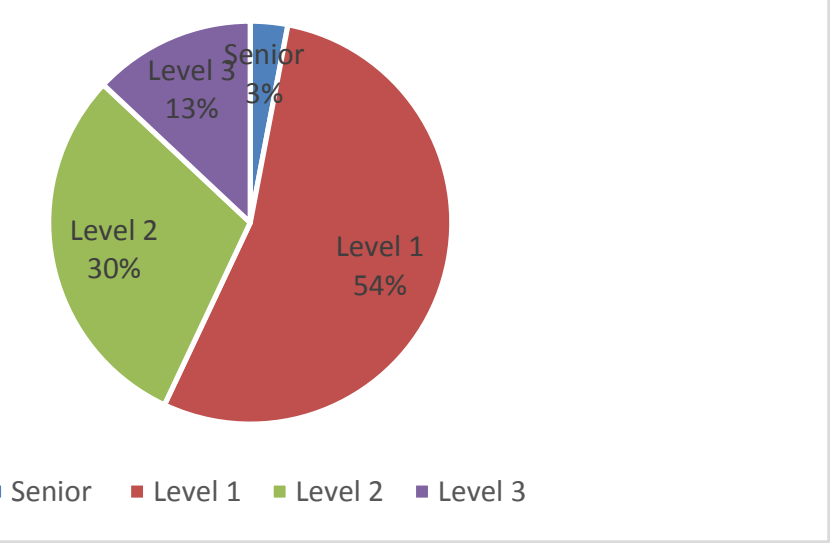

Fig. 1. Distribution of contractors 
As we can observe from the results of Fig.1, only 3\% of the contractors were senior and $54 \%$ of them were rank one contractor, 30\% were level 2 and $13 \%$ of them were level 3 contractor. There were eight questions in our survey and Table 1 demonstrates the description of questions and Table 2 shows details of answers for five Likert scale.

\section{Table 1}

Eight questions of the survey

\begin{tabular}{|c|c|}
\hline Question & Description \\
\hline 1 & $\begin{array}{l}\text { Giving full authority to project team members for accomplishment of the assignment, except for the } \\
\text { completion of work }\end{array}$ \\
\hline 2 & $\begin{array}{l}\text { Specifying details of the project by the project team and the client during the implementation of the } \\
\text { project }\end{array}$ \\
\hline 3 & Implementation of project work based on client’s priorities \\
\hline 4 & $\begin{array}{l}\text { Changes in project work during the construction phase and implementation by the project team and the } \\
\text { client during the implementation of the project }\end{array}$ \\
\hline 5 & Integrated performance standards for all stages of construction and construction works \\
\hline 6 & $\begin{array}{l}\text { Evaluation system for implementation and construction phase of the work, before the initiation of the } \\
\text { work }\end{array}$ \\
\hline 7 & $\begin{array}{l}\text { Determine the progress of the project based on project work breakdown structure and not based on task } \\
\text { weight and cost }\end{array}$ \\
\hline 8 & $\begin{array}{l}\text { Active participation of the employer or his/her legal representative on the project team to accelerate the } \\
\text { decision-making }\end{array}$ \\
\hline
\end{tabular}

\section{Table 2}

The summary of Likert scale description

\begin{tabular}{ll}
\hline Scale & Description \\
\hline 0 & It is impossible to do it. \\
1 & There is a little chance to do to. \\
\hline 3 & There is some possibility for accomplishment of the task. \\
\hline 4 & It is possible to do it. \\
\hline
\end{tabular}

In this survey, all eight questions presented in Table 1 are presented to top management of existing 35 contractors and they are asked to choose one of the scales given in Table 2. The survey was accomplished in terms of four perspectives namely, culture, projects, tools and processes. Fig. 2 demonstrates the means given to each question.

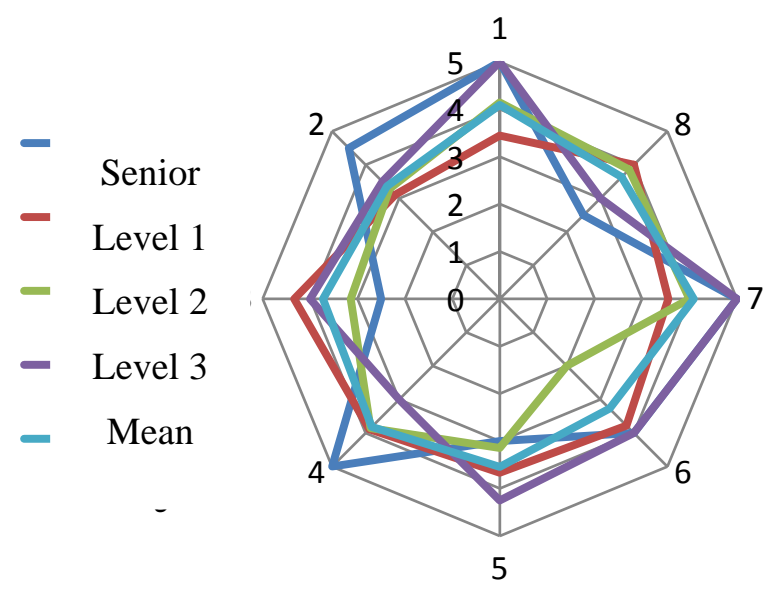

Mean of questions in terms of culture

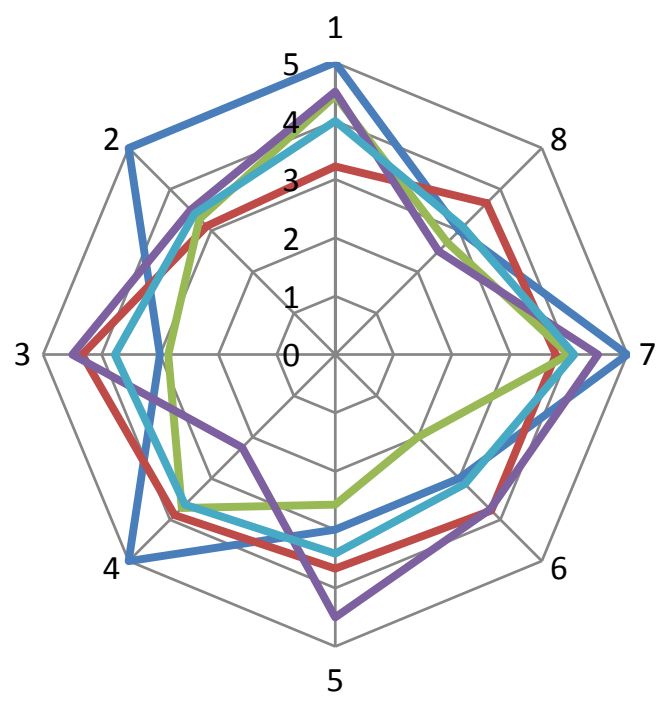

Mean of questions in terms of project 


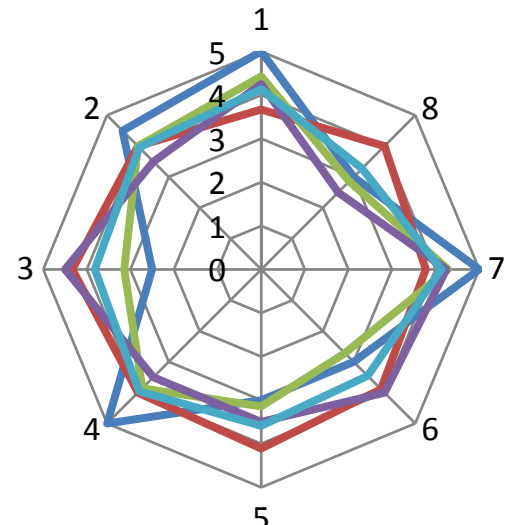

Mean of questions in terms of tools

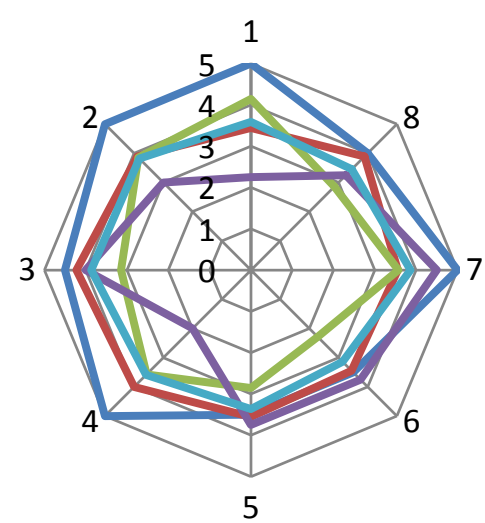

Mean of questions in terms of employee

Fig. 2. The mean of responses to different groups of questions in terms of culture, project, tools and processes and employee

\section{Results and discussion}

In this section, we present details of our findings on experts' insight on the capabilities of using agile contractors to promote mass housing contractors.

Table 3

The results of binomial test

\begin{tabular}{|c|c|c|c|c|c|c|c|c|c|c|c|c|c|}
\hline & $\mathrm{Q}$ & Categor & Obs. & Prob. & Test & Obs. & & $\mathrm{Q}$ & Categ & Obs. & Pro & Test & Obs. \\
\hline \multirow{24}{*}{$\begin{array}{r}\text { Cultur } \\
\mathrm{e}\end{array}$} & 1 & $<=2$ & 2 & 0.07 & 0.5 & $.000^{\mathrm{a}}$ & & 1 & $<=2$ & 3 & 0.1 & 0.5 & $.000^{\mathrm{a}}$ \\
\hline & & $>2$ & 28 & 0.93 & & & & & $>2$ & 27 & 0.9 & & \\
\hline & 2 & $<=2$ & 8 & 0.27 & 0.5 & $.016^{a}$ & & 2 & $<=2$ & 7 & 0.2 & 0.5 & $.005^{a}$ \\
\hline & & $>2$ & 22 & 0.73 & & & & & $>2$ & 23 & 0.7 & & \\
\hline & 3 & $<=2$ & 10 & 0.33 & 0.5 & $.099^{\mathrm{a}}$ & & 3 & $<=2$ & 10 & 0.3 & 0.5 & $.099^{\mathrm{a}}$ \\
\hline & & $>2$ & 20 & 0.67 & & & & & $>2$ & 20 & 0.6 & & \\
\hline & 4 & $<=2$ & 3 & 0.1 & 0.5 & $.000^{a}$ & & 4 & $<=2$ & 7 & 0.2 & 0.5 & $.005^{a}$ \\
\hline & & $>2$ & 27 & 0.9 & & \multicolumn{3}{|c|}{ Projects } & $>2$ & 23 & 0.7 & & \\
\hline & 5 & $<=2$ & 7 & 0.23 & 0.5 & $.005^{a}$ & & 5 & $<=2$ & 8 & 0.2 & 0.5 & $.016^{a}$ \\
\hline & & $>2$ & 23 & 0.77 & & & & & $>2$ & 22 & 0.7 & & \\
\hline & 6 & $<=2$ & 9 & 0.3 & 0.5 & $.043^{a}$ & & 6 & $<=2$ & 11 & 0.3 & 0.5 & $.200^{\mathrm{a}}$ \\
\hline & & $>2$ & 21 & 0.7 & & & & & $>2$ & 19 & 0.6 & & \\
\hline & 7 & $<=2$ & 2 & 0.07 & 0.5 & $.000^{a}$ & & 7 & $<=2$ & 1 & 0.0 & 0.5 & $.000^{\mathrm{a}}$ \\
\hline & & $>2$ & 28 & 0.93 & & & & & $>2$ & 29 & 0.9 & & \\
\hline & 8 & $<=2$ & 5 & 0.17 & 0.5 & $.000^{a}$ & & 8 & $<=2$ & 12 & 0.4 & 0.5 & $.362^{\mathrm{a}}$ \\
\hline & & $>2$ & 25 & 0.83 & & & & & $>2$ & 18 & 0.6 & & \\
\hline & $\mathrm{Q}$ & Categor & Obs. & Prob. & Test & Obs. & & $\mathrm{Q}$ & Categ & Obs. & Pro & Test & Obs. \\
\hline & 1 & $<=2$ & 3 & 0.1 & 0.5 & $.000^{\mathrm{a}}$ & & 1 & $<=2$ & 6 & 0.2 & 0.5 & $.001^{\mathrm{a}}$ \\
\hline & & $>2$ & 27 & 0.9 & & & & & $>2$ & 24 & 0.8 & & \\
\hline & 2 & $<=2$ & 4 & 0.13 & 0.5 & $.000^{a}$ & & 2 & $<=2$ & 7 & 0.2 & 0.5 & $.005^{a}$ \\
\hline & & $>2$ & 26 & 0.87 & & & & & $>2$ & 23 & 0.7 & & \\
\hline & 3 & $<=2$ & 10 & 0.33 & 0.5 & $.099^{\mathrm{a}}$ & & 3 & $<=2$ & 7 & 0.2 & 0.5 & $.005^{a}$ \\
\hline & & $>2$ & 20 & 0.67 & & & & & $>2$ & 23 & 0.7 & & \\
\hline & 4 & $<=2$ & 4 & 0.13 & 0.5 & $.000^{\mathrm{a}}$ & Employee & 4 & $<=2$ & 11 & 0.3 & 0.5 & $.200^{\mathrm{a}}$ \\
\hline Tools & & $>2$ & 26 & 0.87 & & & & & $>2$ & 19 & 0.6 & & \\
\hline & 5 & $<=2$ & 8 & 0.27 & 0.5 & $.016^{a}$ & & 5 & $<=2$ & 10 & 0.3 & 0.5 & $.099^{\mathrm{a}}$ \\
\hline & & $>2$ & 22 & 0.73 & & & & & $>2$ & 20 & 0.6 & & \\
\hline & 6 & $<=2$ & 5 & 0.17 & 0.5 & $.000^{a}$ & & 6 & $<=2$ & 8 & 0.2 & 0.5 & $.016^{\mathrm{a}}$ \\
\hline & & $>2$ & 25 & 0.83 & & & & & $>2$ & 22 & 0.7 & & \\
\hline & 7 & $<=2$ & 2 & 0.07 & 0.5 & $.000^{\mathrm{a}}$ & & 7 & $<=2$ & 3 & 0.1 & 0.5 & $.000^{a}$ \\
\hline & & $>2$ & 28 & 0.93 & & & & & $>2$ & 27 & 0.9 & & \\
\hline & 8 & $<=2$ & 9 & 0.3 & 0.5 & $.043^{a}$ & & 8 & $<=2$ & 9 & 0.3 & 0.5 & $.043^{a}$ \\
\hline & & $>2$ & 21 & 0.7 & & & & & $>2$ & 21 & 0.7 & & \\
\hline
\end{tabular}


According to Table 3, in terms of culture and tools, except the third question, most experts believed that it would be easy to implement agile concept to promote mass housing contracts. In other words, experts did not agree that implementation of project work could be accomplished based on client's priorities. In terms of projects, contractors' representatives agreed on most questions we asked except the third and the eighth questions. Finally, in terms of processes, agreed on 6 items we asked and disagree about fourth and fifth items. Overall, it appears that agile concept could be implemented in construction projects as well as it had been applied in many software engineering projects.

\section{Conclusion}

In this paper, we have presented an empirical investigation to study the possibility of implementing agile concept to promote mass housing contractors. The study has categorized the survey into four groups and the results of our survey have indicated that, in terms of culture, tools and project, the implementation of the project's work must be based on the priority of the employer. In terms of project, evaluation system for implementation and construction phase of the work must be done before the enforced. In addition, active participation of the employer or his/her legal representative on the project team must exist to accelerate the decision-making. Experts believed that change in work in process to build and to run the project must be accomplished by the project team and the client by both groups during the implementation of the project. Finally, an integrated performance standards for all stages of construction and construction works must exist within the construction operations.

\section{Acknowledgement}

The authors would like to thank the anonymous referees for constructive comments on earlier version of this paper.

\section{References}

Augustine, S. (2005). Managing agile projects. Prentice Hall PTR.

Boehm, B., \& Turner, R. (2003a). Balancing agility and discipline: A guide for the perplexed. AddisonWesley Professional.

Boehm, B., \& Turner, R. (2003b). Observations on balancing discipline and agility. In Agile Development Conference, 2003. ADC 2003. Proceedings of the (pp. 32-39). IEEE.

Chow, T., \& Cao, D. B. (2008). A survey study of critical success factors in agile software projects. Journal of Systems and Software, 81(6), 961-971.

Cockburn, A., \& Highsmith, J. (2001). Agile software development: The people factor. Computer, 34(11), 131-133.

Drury, M., Conboy, K., \& Power, K. (2012). Obstacles to decision making in Agile software development teams. Journal of Systems and Software, 85(6), 1239-1254.

Highsmith, J. (2002). Agile software development ecosystems. Addison-Wesley Longman Publishing Co., Inc..

Koch, A. S. (2005). Agile software development: evaluating the methods for your organization. Boston: Artech house.

Racheva, Z., Daneva, M., Sikkel, K., Herrmann, A., \& Wieringa, R. (2010, September). Do We Know Enough about Requirements Prioritization in Agile Projects: Insights from a Case Study. In $R E$ (pp. 147-156).

Schuh, P. (2005). Integrating agile development in the real world (Vol. 1). Hingham: Charles River Media.

Sidky, A., \& Smith, G. (2009). Becoming Agile in an imperfect World.

Shrivastava, S. V., \& Rathod, U. (2015). Categorization of risk factors for distributed agile projects. Information and Software Technology, 58, 373-387. 
542

Vinodh, S., Devadasan, S. R., Vimal, K. E. K., \& Kumar, D. (2013). Design of agile supply chain assessment model and its case study in an Indian automotive components manufacturing organization. Journal of Manufacturing Systems, 32(4), 620-631. 